\title{
Erratum to: ReLaTIve. An Ansi C90 software package for the Real Laplace Transform Inversion
}

\author{
Luisa D'Amore • Rosanna Campagna • \\ Valeria Mele • Almerico Murli • \\ Mariarosaria Rizzardi
}

Published online: 10 June 2013

(C) Springer Science+Business Media New York 2013

\section{Erratum to: Numer Algor (2013) 63:187-211 \\ DOI 10.1007/s11075-012-9636-0}

We regret to mention that the name of M. Rizzardi, Parthenope University, Naples, Italy was missing amongst the listed authors. The complete authors are indicated here. The paper should be referenced with the full list of authors as L. D'Amore, R. Campagna, V. Mele, A. Murli, M. Rizzardi.

The online version of the original article can be found at http://dx.doi.org/10.1007/s11075-012-9636-0

L. D’Amore $(\triangle) \cdot$ R. Campagna · V. Mele

Department of Mathematics and Applications,

University of Naples Federico II, Naples, Italy

e-mail: luisa.damore@unina.it

R. Campagna

e-mail: rosanna.campagna@unina.it

V. Mele

e-mail: valeria.mele@unina.it

A. Murli

CMCC (Centro Euro-Mediterraneo sui Cambiamenti Climatici), Lecce, Italy

e-mail: almerico.murli@cmcc.it

M. Rizzardi

Parthenope University, Naples, Italy 